\title{
Tomato Purple Leaf Disorder: A New Challenge for the Tomato Industry in Florida ${ }^{1}$
}

\begin{abstract}
Gary E. Vallad, Bielinski M. Santos, Jane E. Polston, David J. Schuster, Andrew W. MacRae, Jeremy D. Edwards, and John W. Scott ${ }^{2}$
\end{abstract}

\section{Symptoms and Field Distribution}

The tomato purple leaf disorder (TPLD) has been observed in several tomato fields in Hillsborough, Manatee, and Miami-Dade counties since 2006. Initial symptoms appear between six and eight weeks after transplanting and could be somewhat confused with mild phosphorus (P) deficiency. However, nutritional analysis of leaves obtained from three affected locations revealed normal values for all essential nutrients, including P.

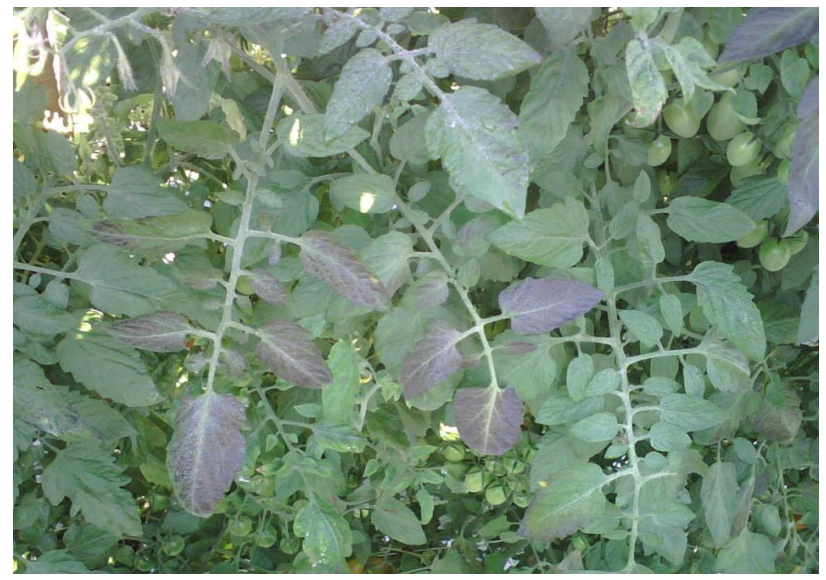

The key diagnostic difference between TPLD symptoms and the symptoms of $\mathrm{P}$ deficiency is that symptoms of $\mathrm{P}$ deficiency first appear on the lower leaf surface, causing vein purpling, and then extend to the whole leaf. By contrast, TPLD tends to appear primarily on the upper leaf surface, without affecting the veins, and gradually spreads to the entire leaf surface (figures 1, 2 and 3).

Often, when one leaf overlaps another, TPLD only develops on the surface portion exposed to sunlight, with the shaded leaf tissues remaining green

Figure 1. Initial interveinal purpling of tomato leaf. Credits: B.M. Santos

(Fig. 4). No deformation or bronzing of the affected leaves has been observed. Instead, these leaves appear to senesce prematurely (Fig. 5). This disorder can occur in all types of cultivated tomatoes (i.e. grape, cherry, round and Roma types), but the severity of the damage appears to vary among types and cultivars. The effect of TPLD on yield is unknown.

1. This document is PP259, one of a series of the Plant Pathology Department, Florida Cooperative Extension Service, Institute of Food and Agricultural Sciences, University of Florida. Original publication date, November 2008. Visit the EDIS Website at http://edis.ifas.ufl.edu.

2. Gary E. Vallad, assistant professor, Plant Pathology Deptartment, and Bielinski M. Santos, assistant professor, Horticultural Sciences Department, Gulf Coast Research and Education Center (GREC) -- Wimauma, FL; Jane E. Polston, professor, Plant Pathology Department, Gainesville, FL; David J. Schuster, professor, Entomology and Nematology Department, Andrew W. MacRae and Jeremy D. Edwards, assistant professors, and John Scott, professor, Horticultural Sciences Department, GREC -- Wimauma, FL, Institute of Food and Agricultural Sciences, University of Florida. 


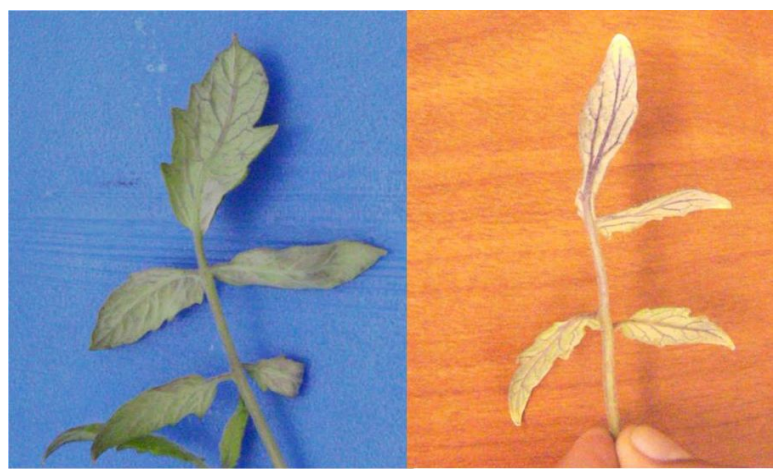

Figure 2. Phosphorus deficiency in tomato leaves. Note the veinal purpling on lower leaf surface. Credits: B.M. Santos

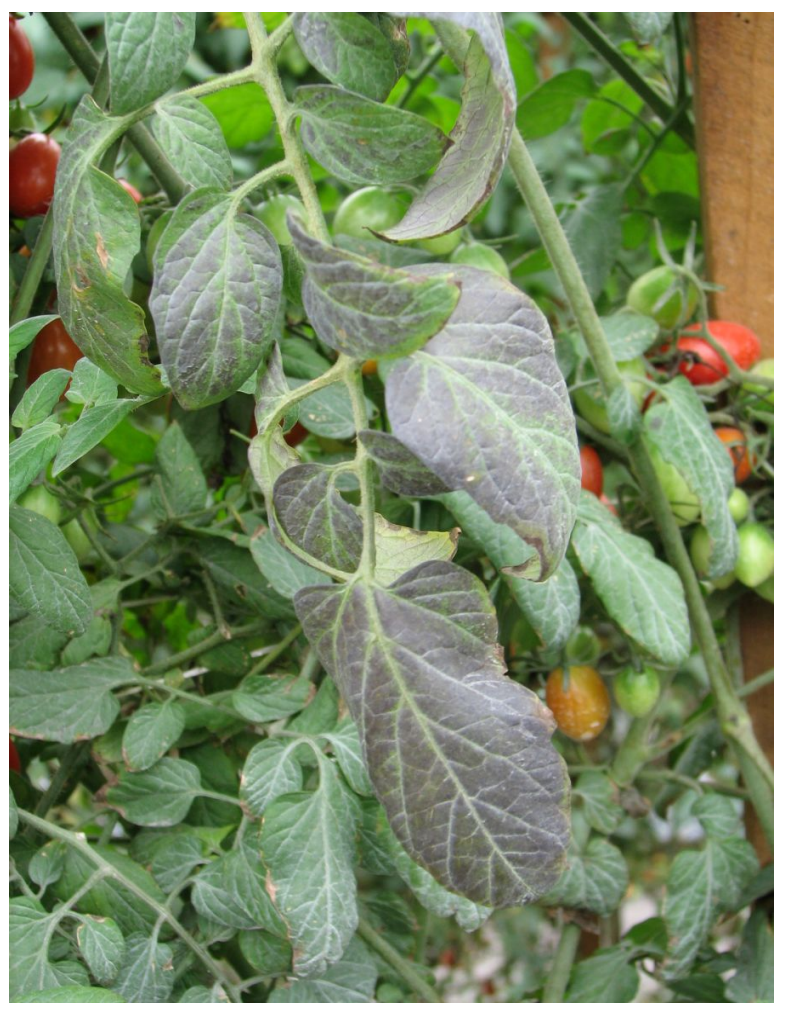

Figure 3. Severe interveinal purpling of tomato leaf. Credits: A. MacRae

Field distribution of TPLD remains a subject of further research. However, some preliminary data were collected from affected fields in South Florida to determine the incidence and distribution of the disorder. At 11 weeks after transplanting, the incidence of TPLD was less than 1 percent (one or two plants per 600 feet of row). However, four weeks later, incidence in the same field increased to more than 90 percent. An adjacent field under the same management practices, which was four weeks younger than the previous one, exhibited mild TPLD infestation with less than 25 percent incidence. No

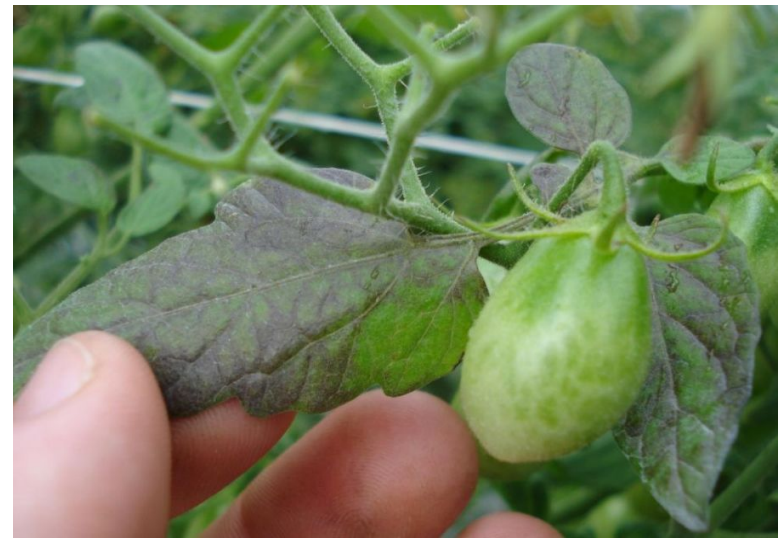

Figure 4. A leaf petiole that was partially shaded by the developing fruit. Note that the shaded region remained green. Credits: A. MacRae

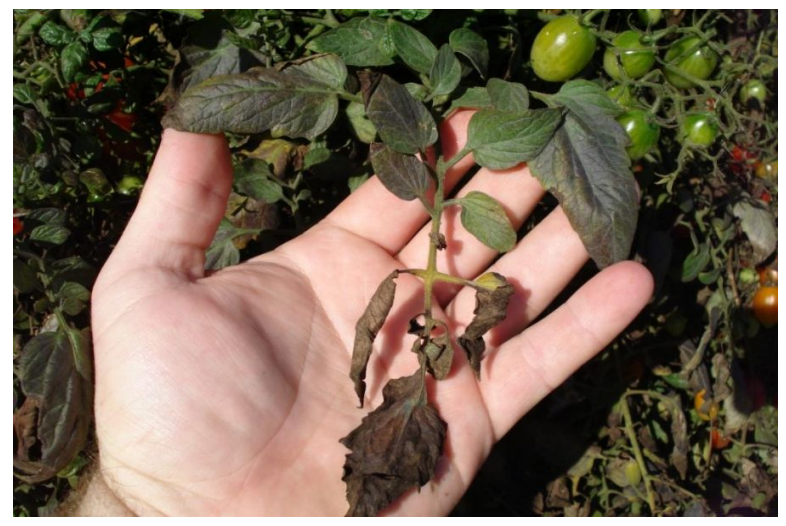

Figure 5. Apparent decline and premature senescence of tomato leaves affected by tomato purple leaf disorder. Credits: A. MacRae

clear pattern of distribution was observed with respect to incidence within a bush or a row or in relation to the prevailing sun and wind direction. Further studies need to be conducted to confirm these observations.

Tests for known pathogens of tomato using standard microbiological, serological, and nucleic acid-based methods were negative. However, preliminary studies suggest that TPLD is caused by an infectious agent, like a virus or viroid. The mechanism of transmission is still unknown. As new information emerges, subsequent articles and fact sheets will follow to update the industry on findings and recommendations. 